\title{
DEZ OBSERVAÇÕES SOBRE MÍDIA E VIOLÊNCIA
}

\section{As imagens de violência na mídia extrapolam o fato social em si, tornam-se um mecanismo comercial: têm audiência garantida e atraem anunciantes}

Embora tenhamos uma palavra genérica para os meios de comunicação - mídia -, o que ocorre neles não é sempre homogêneo e igual. Há diversos públicos, veículos e, por isso, alguns tratamentos diferenciados sobre o tema da violência.

Exploro neste artigo dez observações recorrentes e repetitivas daquilo que podemos sintetizar como sendo tratamento que a mídia dá à violência.

1. A respeito da influência da violência transmitida pela mídia sobre o comportamento violento, os estudos têm indicado que não há uma relação necessária entre transmissão da violência e adoção de um comportamento violento. A partir de várias pesquisas, principalmente norte-americanas, o que se consegue afirmar a respeito da influência dos programas de televisão e dos filmes de conteúdos violentos no aumento da criminalidade é que necessariamente a violência das telas não condiciona as atitudes violentas.

\section{A AUTORA}

\section{Elisabeth Rondelli}

Professora e pesquisadora do Núcleo de Estudos e Projetos em Comunicação (Nepcom), da Escola de Comunicação da UFRJ. Editora da revista Comunicação \& Política, do Centro Brasileiro de Estudos Latino-Americanos.
Tal efeito pode ser produzido quando a divulgação desses conteúdos aparece associada a outros fatores como, por exemplo, predisposições psicológicas - indivíduos que são, por natureza, mais agressivos - e convívio em ambientes sociais cujo universo de valores propiciem a existência de frouxos controles às erupções dos atos violentos, ou mesmo que os valorizem positivamente.

\section{Destaque da violência}

2. A mídia apropria-se da violência e do crime como matéria-prima de seus programas jornalísticos e ficcionais.

É certo que violência e crime vendem noticia, trazem leitores para os jornais e audiência para as emissoras de televisão que os tomam como elemento de disputa de telespectadores.

É sabido que o aumento da audiência do telejornal Aqui Agora fez com que os telejornais RJTV e o SPTV aumentassem a presença de notícias sobre violência e crime em suas edições. Portanto, isto pode significar que, necessariamente, pode não ter havido na realidade um aumento de atos violentos ou criminosos, mas maior dedicação de espaço a notícias sobre eles. 
Os romances e filmes policiais e de guerra exploram este filão do gosto público pela violência e criminalidade, assim como o fazem os jornais e a televisão. Por causa deste gosto público é que os crimes se prestam a serem trabalhados a partir de relatos sensacionais e dramáticos, sendo Gil Gomes, do telejornal Aqui Agora, um dos mestres deste tipo de narração.

3. O tratamento que a mídia dá à violência pode estar construindo uma estigmatização generalizada contra os pobres e a pobreza e contribuindo para a edificação de um separatismo social.

O modo como a mídia nomeia e trata o crime, os criminosos, os seus praticantes, as suas vítimas e os lugares onde eles ocorrem, pode estar produzindo duas coisas: a) uma associação entre crimes e pobres; por dedução, todos os pobres são potenciais criminosos e devem ser evitados/afastados, se não, eliminados; b) uma banalização do crime e da violência, de modo a que nos tornemos cada dia mais insensíveis às suas ocorrências, julgando-as naturais em nosso convívio.

4. Ao mesmo tempo em que a mídia pode contribuir para banalizar a nossa visão sobre o crime, ela pode estar tendo uma ação pedagógica positiva que é a de nos sensibilizar em relação à sua existência e frequiência, e nos induzir a um sentimento de indignação moral diante do crime, que nos mova a pedir soluções para o seu controle. Neste sentido, a mídia tornase uma caixa de ressonância da opinião pública ou, ao menos, daqueles que têm acesso à mídia.

5. Entretanto, ao fazer isto, a mídia pode estar produzindo não necessariamente uma indignação moral que motive atitudes para o controle do crime e da violência, mas construindo a visão de uma sociedade des- governada, sem normas, sem ordem, onde os indivíduos têm, sobretudo, medo.

Neste sentido, esta manufatura do medo pela mídia pode demandar apenas atitudes policiais ou militares repressivas, não importa a que preço, uma vez que do medo podem ser geradas atitudes irracionais.

\section{Estado de defesa}

Esta imagem de uma sociedade fora do controle legal não é construída somente nos tratamentos que a mídia dá aos crimes e à violência contra a pessoa, mas também quando mostra crimes de outra natureza. Assim os crimes econômicos, políticos, oriundos da corrupção, contribuem para se construir a visão de uma sociedade decadente do ponto de vista moral. Esta visão cria dificuldades para a edificação de uma cultura solidária, pois o outro é sempre visto como um potencial inimigo de quem se deve, sobretudo, desconfiar.

Quantos de nós já não fomos interceptados inesperadamente na rua para um pedido qualquer de ajuda momentânea e não ficamos na dúvida, extremamente desconfiados e antecipadamente armados, em relação às reais intenções daquele que nos interpela, mesmo quando o que se pede é uma simples informação? Esse susto provocado pela abordagem, às vezes injustificado, vem de um estado constante de alerta contra o outro a que nos condicionamos. Podem ter uma causa real ou imaginária, mas indicam, sobretudo, o medo do outro, um estatuto de certa individualidade que nos convoca a estar sempre em estado de defesa. Os jornais muitas vezes divulgam matérias sobre como devemós nos defender: não andar à noite, não parar nos sinais desertos, não saltar do carro sem olhar ao redor, não, não, não... 
6. A mídia também funciona como um tribunal que levanta os fatos, sentencia e julga. Isto ocorre porque na ausência de instâncias policiais e judiciárias que cumpram este papel é a mídia que o preenche. É o caso, por exemplo, do Aqui Agora, telejornal onde o repórter investiga o crime, denuncia ou defende os envolvidos e antecipa as sentenças.

Esses programas estão construindo uma justiça e uma ética próprias, paralelas à dos mecanismos policiais e jurídicos formais.

Edificam-se como verdadeiros tribunais mediáticos, independentes de qualquer direito, mas submetidos às exigências dos interesses das emissoras, dos anunciantes e dos presumíveis receptores.

7. O tratamento que a mídia dá à violência e ao crime geralmente dissocia os fatos de tal modo que os crimes econômicos ou de corrupção, por exemplo, podem não aparecer como uma das causas da outra criminalidade mais difusamente espalhada pela sociedade. O desvio ilegal de verbas públicas de programas de saúde ou nutrição poderiam, de forma indireta, matar pessoas que deles dependem, mas estes dois pólos da ação - o desvio da verba e a provocação da morte - não são relacionados e nem seus atores denunciados, uma vez que tais atos de corrupção geralmente se perdem nas redes de uma instituição burocrática difícil de identificar. Os chamados crimes contra a pessoa - um roubo de casa, um assalto na rua, um homicídio - são mais visíveis, detectáveis e passíveis de serem transformados em imagens dos noticiários do que estes outros crimes da corrupção, menos sujeitos a serem apreendidos por qualquer imagem. Neste sentido, mais importante do que a natureza e a dimensão do crime, o que importa é a sua potencialidade de gerar imagens.

\section{Ricos e pobres, jovens e negros}

8. A televisão tece identidades. Por isso, um olhar mais atento sobre ela mostra que há uma televisão dos ricos e uma televisão dos pobres, para falar de maneira grosseira e dicotômica. Essa segmentação está presente nos gêneros e estilos dos programas para os pobres, os de auditório, por exemplo; nos horários da programação (das $18 \mathrm{~h}$ às $22 \mathrm{~h}$, esta é a mais popularesca, de um modo geral); e no estilo das emissoras (SBT e Globo têm públicos com perfis sócio-econômicos diferentes e, portanto, diferentes programas dirigidos a cada um destes perfis).

Isto mostra que a televisão tem uma fórmula já pronta para diferenciar segmentos e operar construções imaginárias e identificatórias sobre ricos, pobres e suas respectivas estigmatizações.

9. A relação entre os jovens e a violência aparece na mídia também de forma estigmatizadora. Pois são os jovens os principais atores e vítimas do crime. Mas são eles também os responsáveis pela emergência de uma crítica social que não está hoje tão acentuadamente nos sindicatos e nos movimentos sociais que ganharam enorme expressão nos anos 80 . Uma característica importante dos anos 90 é que a crítica social é, sobretudo, a expressão de um sentimento de exclusão social. E ser jovem, pobre (e negro) é ser o excluído preferencial. É experimentar a exclusão de forma muito perversa, pois tais excluídos são julgados economicamente desnecessários, politicamente incômodos, socialmente ameaçadores e considerados passíveis de serem fisicamente exterminados. Daí advindo que as suas identidades não são construídas pela inserção no mundo do trabalho mas a partir da situação de excludência. Dentre outras formas, o 
funk, o rap e outros movimentos similares aparecem como as manifestações críticas da imersão dos jovens nesta cultura de excludência e de violência. E que os meios de comunicação também não deixam de tratar de forma estigmatizadora - os bailes sempre são associados com violência e droga - e não como uma expressão estético-política de uma crítica social.

10. E, finalmente, o caso do Rio de Janeiro, cuja imagem, nas transmissões jornalísticas destinadas a todo o país, é associada com a violência e á necessidade de seu controle, mesmo que este seja um controle militar. É difícil saber o quanto desta imagem tem um fundamento exclusivamente real ou fruto de estragégias do modo de falar da televisão.

Uma pesquisa sobre o tema mídia e violência poderia levantar, por exemplo, algumas questões específicas: a) Em termos absolutos, os crimes praticados em São Paulo, por exemplo, são menores do que os crimes praticados no Rio de Janeiro? b) Não há tráfico e consumo de drogas em cidades como São Paulo, Brasília e outras capitais do Nordeste? Se há, por que a televisão não mostra? c) Por que a maioria dos crimes

Resumo: $\mathrm{O}$ artigo trata da violência veiculada pelos programas de televisão. A autora levanta dez abordagens sobre o problema. Entre elas, destacam-se: a influência da programação violenta sobre o comportamento do público; a estratégia de captar audiência e anúncios com a veiculaçăo de temas violentos; relação entre jovens e criminalidade; a mídia e sua capacidade de julgar o crime e o criminoso; estigmatização da pobreza como violenta.

Palavras-chave: mídia, violência, televisão, telejornais, Rede Globo, SBT. apresentados no Aqui Agora são paulistas e não cariocas?

Tais perguntas poderiam nos revelar a compreensão de algumas hipóteses. Talvez os crimes estejam sendo reportados pela televisão e contribuindo para edificar a imagem de uma cidade violenta, não só porque ela efetivamente o é, mas principalmente porque a imagem que se tem sobre a violência está passando pela pauta da produção dos telejornais. As emissoras de TV de maior audiência, como é sabido, têm grande parte de suas equipes de jornalismo sediadas no Rio de Janeiro (Globo) e São Paulo (SBT). Portanto maior potencial de cobertura dos fatos nestas respectivas cidades e delas, os fatos preferencialmente noticiáveis são aqueles do crime e da violência.

$\mathrm{O}$ mesmo fator que explica porque o Aqui Agora explora mais os crimes paulistas, pode estar explicando porque a Globo explora mais os crimes cariocas. E não é necessariamente porque sejam muitos. Será, principalmente, porque a equipe jornalística destas emissoras é numerosa nestas cidades. Isso faz com que o Rio de Janeiro, por exemplo, se exceda como o lugar da violência em todas as imagens dos noticiários.

Abstract: The article is about violence shown on TV programs. The author points out ten different approaches for the problem. Among them the most important ones are: the influence of violent programs on TV viewers; the strategy of getting more viewers and publicity by means of violent themes; relationship between young people and criminality; the midia and its capacity to juge the crime and the criminal and the stigmatization of poverty and the city of Rio de Janeiro as violent.

Key-words: midia, violence, television, news, Globo and SBT stations. 